\title{
ANALISIS SEMIOTIKA SENAPUR (DAPUR) SEBAGAI PUSAT KEBUDAYAAN
}

\author{
Aka Kurnia SF ${ }^{1}$, Deddy Suprapto ${ }^{2}$, Sutarjon ${ }^{3}$ \\ Fakultas Ilmu Komunikasi \\ Universitas Teknologi Sumbawa, Sumbawa, Indonesia \\ e-mail: aka.kurnia@uts.ac.id
}

\begin{tabular}{|l|c|c|}
\hline (C) (P) & \multicolumn{3}{|c|}{$\begin{array}{l}\text { This is an open-access article under the CC BY-SA license. } \\
\text { Copyright (O) } 2020 \text { by Author. Published by Universitas Pendidikan Ganesha. }\end{array}$} \\
\hline Received : May, 2020 & Accepted : June, 2020 & Published : June, 2020 \\
\hline
\end{tabular}

\begin{abstract}
ABSTRAK
Penelitian ini bertujuan untuk melihat bagaimana senapur (dapur) sebagai pusat kebudayaan. Objek penelitian ini adalah ruang senapur di Rumah tradisional masyarakat Desa Tepal, Kecamatan Batu Lanteh, Kabupaten Sumbawa. Penelitian ini menggunakan pendekatan kualitatif dengan analisis semiotika Roland Barthes yang menekankan pada denotasi, konotasi dan mitos. Hasil penelitian ini menunjukkan bahwa ruang senapur sebagai pusat aktivitas masyarakat tidak hanya memiliki fungsi teknis untuk memasak makanan tetapi juga mempunyai fungsi sosial, budaya dan ritual. Senapur juga menjadi bukti betapa masyarakat Tepal memiliki pemahaman dan kecerdasan sosial yang tinggi.
\end{abstract}

Kata-kata kunci: Dapur, kebudayaan, semiotika, Tepal, Sumbawa

\section{ABSTRACT}

This study aims to see how senapur (kitchen) as a cultural center. The object of this research is the senapur room in the traditional house of the Tepal Village community, Batu Lanteh District, Sumbawa Regency. This study uses a qualitative approach with Roland Barthes's semiotic analysis which emphasizes denotation, connotation and myth. The results of this study indicate that senapur space as a center of community activity not only has a technical function for cooking food but also has sosial, cultural and ritual functions. Senapur is also evidence of how the Tepal people have high understanding and sosial intelligence.

Keywords: Dapur, culture, semiotic, Tepal, Sumbawa

\section{PENDAHULUAN}

Indonesia adalah negara yang kaya akan kebudayaan. Setiap daerah atau wilayah di Indonesia memiliki kebudayaan masing-masing yang berbeda dengan daerah lainnya. Salah satunya adalah rumah tradisional. Hampir setiap daerah memiliki rumah tradisionalnya sendiri, seperti Rumah Gadang di Sumatra Barat, Rumah Joglo di Jawa, Rumah Panggung di Sulawesi, Rumah Honai di Papua dan lain-lain. Demikian pula halnya dengan Sumbawa, juga memiliki rumah tradisional yang berbentuk rumah panggung. 
Rumah tradisional Desa Tepal, Kecamatan Batu Lanteh, Kabupaten Sumbawa, merupakan rumah panggung yang bahan utamanya adalah kayu dan bambu. Bahan-bahan bangunannya merupakan pemanfaatan dari potensi alam (bahan lokal) yang ada disekitarnya. Kontruksi rumah panggung sesuai dengan kondisi alam di Desa Tepal dan sebagai rumah tahan gempa. Daerah ini merupakan termasuk rawan gempa bumi tektonik (patahan Flores di bagian utara dan lempeng Australia di bagian selatan Sumbawa) dan gempa bumi vulkanik (Gunung Tambora dan Gunung Rinjani). Desa Tepal berada pada ketinggian $900 \mathrm{mdpl}$, dengan suhu rata-rata $24^{\circ} \mathrm{C}$ dan musim kemarau pada malam hari mencapai $18^{\circ} \mathrm{C}$.

Masyarakat Tepal dalam membangun rumah panggung dan elemen-elemen interior mempunyai tujuan dan makna sebagai bagian dari kearifan lokal yang sudah ada sejak lama, namun belum didokumentasi dan dipublikasi dengan baik. Seiring perkembangan zaman rumah-rumah di Tepal sudah banyak diubah menjadi rumah tembok permanen dan rangka baja terutama daerah sekitar jalan utama Desa Tepal. Sebagaimana yang dikatakan oleh Winston "Kita membentuk bangunan. Setelahnya, merekalah yang membentuk kita" (Churcill 1874-1965). "Fakta bahwa semua kelompok sosial membangun serta merancang rumah dan bangunan di desa dan kota mereka dengan cara-cara khas merupakan indikasi yang gamblang bahwa bangunan ini juga sistem tanda. Sebuah bangunan hampir tidak pernah dipandang oleh anggota masyarakat tersebut semata-mata sebagai tumpukan bata, kayu, jerami dan sebagainya, yang disusun untuk menyediakan perlindungan. Justru bentuk, ukuran, ciri, dan lokasi bangunan dipandang sebagai penanda yang mengacu pada sebuah lingkup makna yang spesifik pada budaya tersebut" (Danesi, 2010:255).

Menurut Edward Burnett Tylor, dalam bukunya yang berjudul Primitive Culture (1871), ia mendefinisikan pengertian kebudayaan adalah suatu kebulatan yang kompleks dan mencakup pengetahuan, kepercayaan, seni, moral, hukum, adat istiadat, dan kemampuan-kemampuan atau kebiasaan lainnya yang diperoleh manusia sebagai anggota masyarakat. Jadi ruang senapur, bukan hanya dilihat dari fungsi dan bentuk estetikanya saja, tetapi juga sebagai penanda untuk ditafsirkan maknanya sebagai bagian kebudayaan dan kearifan lokal masyarakat Tepal, Sumbawa. penelitian ini mencoba melihat senapur memiliki fungsi yang agak berbeda dengan fungsi dapur pada umumnya.

Senapur adalah bahasa daerah Sumbawa khususnya Desa Tepal yang berarti dapur. Pada umumnya ruang dapur pada sebuah rumah, dibuat untuk melakukan aktivitas memasak makanan untuk disajikan ke ruang makan atau meja makan, namun ruang dapur (senapur) bagi rumah panggung di Desa Tepal, bukan hanya ruang untuk memasak saja, tetapi merupakan ruang yang paling penting dan juga "sakral " serta memiliki bentuk dan elemen interior yang unik. Ruang senapur merupakan ruang yang paling sering digunakan, baik untuk memasak keperluan sehari-hari, maupun digunakan sebagai tempat aktivitas ekonomi lainnya dan tempat bertemu keluarga dan tamu-tamu yang dianggap penting bagi pemilik rumah, untuk membicarakan banyak hal-hal atau peristiwa-peristiwa adat.

\section{METODE}

Penelitian ini adalah penelitian kualitatif yang bertujuan untuk menjelaskan suatu fenomena atau realitas sosial di masyarakat dengan menggunakan pendekatan analisis semiotika Barthes untuk mendeskripsikan tentang senapur di rumah tradisional 
masyarakat Desa Tepal. Barthes meneruskan pemikiran Saussure. Menurut Barthes, semiologi mempelajari tentang bagaimana manusia memaknai sesuatu yang ada di sekitarnya. Objek adalah tanda yang membawa pesan tersirat. Saussure menekankan penandaan pada tataran denotasi dan konotasi. Sementara Barthes menyempurnakan penandaan semiologi Saussure dengan sistem penandaan konotatif dan mitos (Vera, 2014:27).

Makna denotasi adalah mengungkapkan makna yang dilihat oleh mata, artinya makna denotasi adalah makna yang sebenarnya. Jadi, makna denotasi adalah signifikasi pemaknaan tingkat pertama, apa yang dilihat oleh mata itulah yang diyakini kebenarannya. Sedangkan makna konotasi mempunyai makna yang subjektif. Konotasi atau signifikasi pemaknaan tingkat kedua adalah mengungkapkan makna yang terkandung dalam tanda-tanda (Sobur, 2013:262).

Aspek lain dari pemikiran Barthes adalah mitos. Menurutnya cara kerja mitos yang paling penting adalah menaturalisasi sejarah. Hal ini menunjuk pada fakta bahwa mitos sesungguhnya merupakan produk sebuah kelas sosial yang telah meraih dominasi dalam sejarah tertentu: makna yang disebarluaskan melalui mitos pasti membawa sejarah bersama mereka, namun pelaksanaannya sebagai mitos membuat mereka mencoba menyangkalnya dan menampilkan makna tersebut sebagai yang alami, bukan bersifat historis atau sosial (Fiske, 2018: 145).

Pengumpulan data primer diperoleh melalui wawancara ke beberapa narasumber di Desa Tepal. Sementara itu, data sekunder diperoleh melalui studi dokumentasi terhadap dokumen tertulis, hasil-hasil penelitian dan literatur lainnya yang mendukung tujuan penelitian. Data diolah berdasarkan kategori data yang telah ditentukan. Kemudian dianalisis dengan teknik analisa kualitatif, yaitu menjelaskan makna denotasi dan konotasi ruang senapur serta aktivitas di ruang senapur.

\section{HASIL DAN PEMBAHASAN}

Pembagian ruang untuk rumah panggung Desa Tepal terdiri dari tiga ruang. Pertama, rong lu'er di bagian depan digunakan sebagai ruang tamu, ruang tidur tamu dan atau juga sebagai ruang penyimpanan hasil panen. Kedua, rong tenga' sebagai ruang keluarga dan ruang tidur pemilik rumah yang berada di bagian tengah. Ketiga, rong lebang bute' yang berada di bagian belakang, sebagai ruang untuk penyimpanan barang/alat-alat rumah tangga, bahan makanan dan sebagai ruang senapur. 


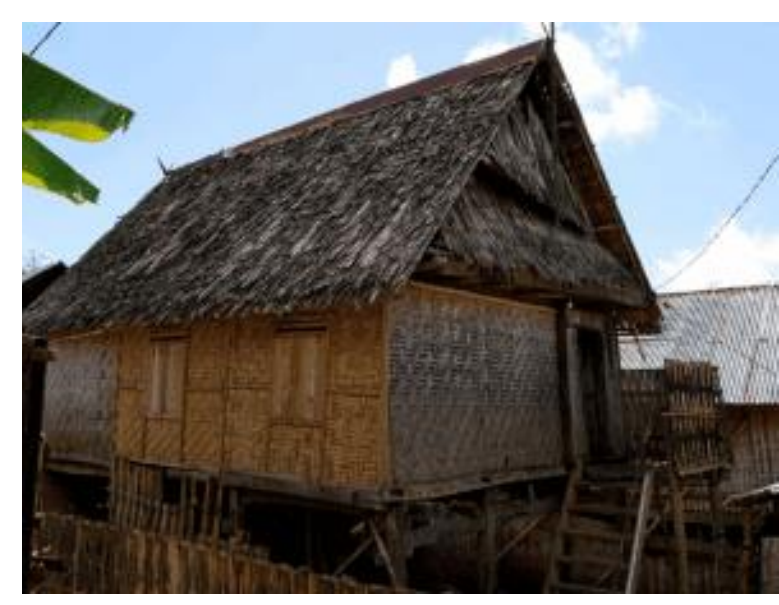

Gambar 1. Rumah Panggung di Desa Tepal

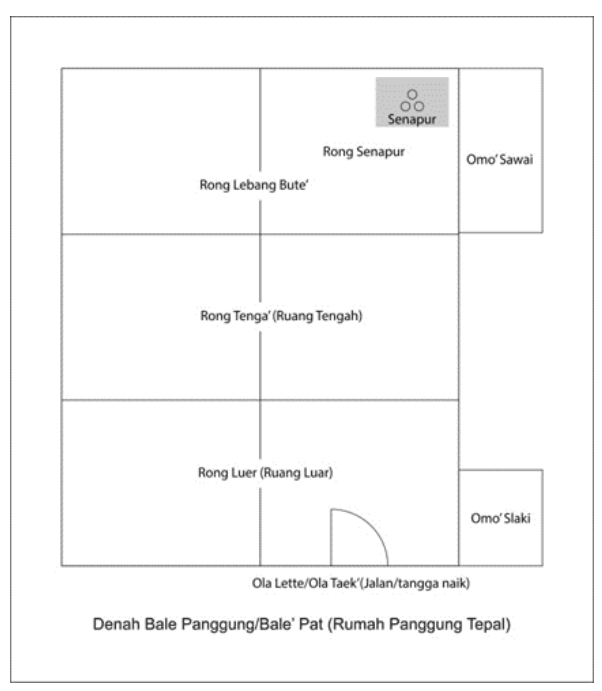

Rumah panggung di Desa Tepal dan juga rumah panggung Sumbawa pada umumnya, sangat fleksibel dalam pembagian ruang, dari ruang privat berubah menjadi ruang publik, tergantung dari kegunaan dan keinginan pemilik rumah, jika pemilik rumah mengadakan acara atau hajatan yang mengundang banyak orang, maka untuk memenuhi jumlah undangan yang hadir maka sekat/dinding rumah panggung bisa dilepas atau dibongkar, karena dinding pemisah atau sekat dapat dibongkar-pasang (knockdown). Semua ruang dalam rumah panggung bisa dialihfungsikan namun senapur (dapur) tidak bisa berubah fungsi dan letaknya. Bahkan senapur ditambah/dibuatkan lagi guna memenuhi kebutuhan memasak untuk makanan para tamu undangan yang lebih banyak.
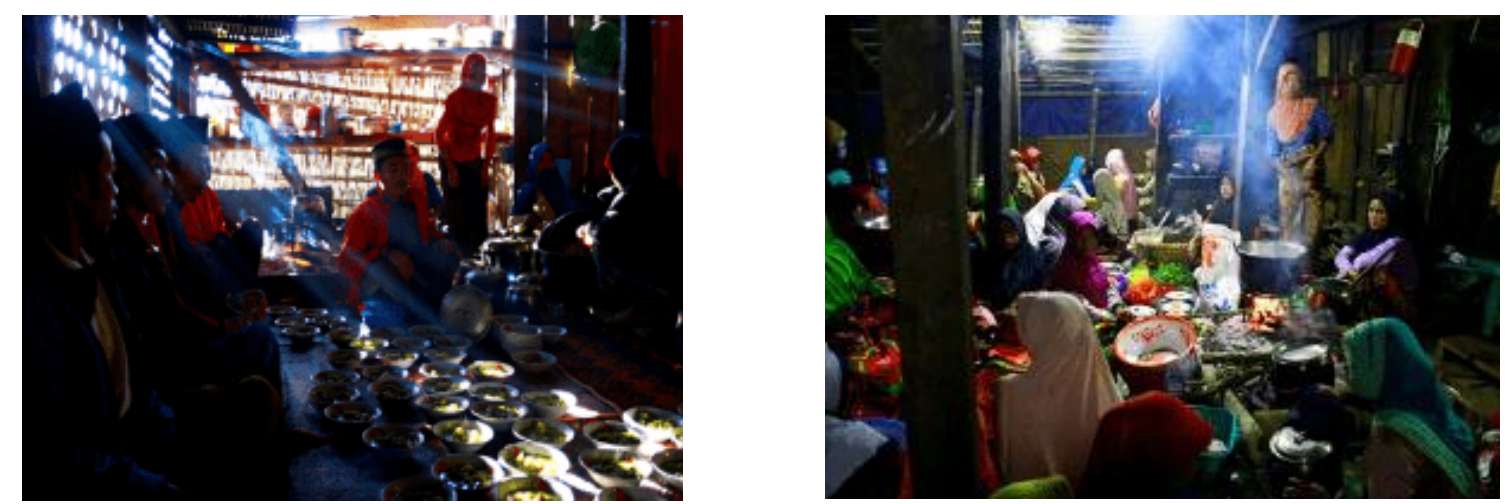

Gambar 2. Ruang Senapur (dapur) Desa Tepal diubah menjadi ruang publik terbuka

Dinding rumah panggung Desa Tepal yang fleksibel menandakan orang Tepal yang egaliter, berjiwa sosial, menghargai kebersamaan, terbuka, menghargai tamu, bersikap ramah, ulet, pekerja keras dan kuat mempertahankan prinsip serta keyakinan. Masyarakat Tepal sangat menghormati tamu, bila ada tamu dari luar desa, mereka akan menawarkan rumahnya untuk menginap, dan juga menawarkan makan, walaupun kondisi rumah dan makanan seadanya, mereka berusaha menjamu tamu dengan sebaik-baiknya, bahkan sedikit berlebih dibandingkan dengan menu keseharian mereka. Bila sehariharinya mereka sekeluarga makan dengan nasi, sayur blunak (pakis) dan sira wer (sambal 
khas Tepal), jika ada tamu, mereka akan berusaha menyembelih ayam sebagai tambahan menu untuk tamu. Mereka percaya dengan menjamu tamu di rumah, sebagai penanda status sosial lebih baik dan menjadi sebuah kehormatan di tengah masyarakat. Lebih daripada itu mereka percaya bahwa tamu merupakan pintu rizki, sekaligus juga implementasi sebuah bentuk nilai ibadah kepada Allah SWT.

\section{Ruang Senapur}

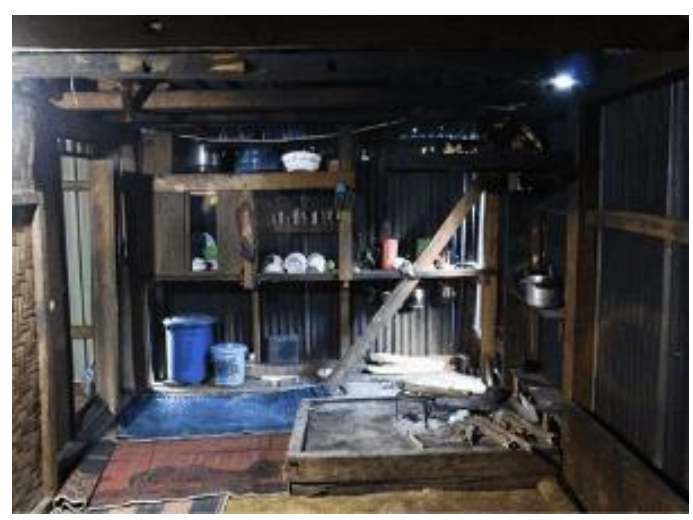

Gambar 3. Ruang senapur (dapur)

\section{Denotasi}

Ruang senapur atau ruang dapur terletak di bagian belakang. Ruangan ini biasanya memiliki ukuran sekitar 3 x 6 meter atau disesuaikan dengan lebar rumah. Selain memiliki fungsi untuk memasak, menyimpan peralatan rumah tangga, menyimpan persediaan makanan, juga untuk melakukan aktivitas sehari-hari, membuat kerajinan seperti bakul, dangan (gagang), bate (sejenis parang yang bergagang panjang), berang (parang). Aktivitas ini dilakukan di dapur karena bahan-bahan kerajinan tersebut biasanya berbahan dasar bambu atau kayu sehingga sisa-sisa bahan yang tidak terpakai lagi dimasukkan ke dalam tungku api. Hal ini memiliki makna pembersihan lahir dan batin dari segala kotoran dan dosa bila hal tersebut dibakar oleh api.

\section{Konotasi}

Senapur juga dijadikan tempat refleksi tentang kehidupan manusia dengan memiliki media tanah, kayu dan api. Tanah mengingatkan tentang asal-usul manusia dan kembalinya manusia (mati), sehingga manusia tidak menjadi sombong dan angkuh dalam kehidupan, tidak bedanya dengan posisi tanah di bawah. Kayu merupakan kehidupan dunia bila ditanam dengan nilai-nilai yang baik maka akan tumbuh menjadi besar dan subur, yang akan memberi manfaat yang lebih besar terhadap kehidupan di dunia. Sementara api menandakan untuk selalu interospeksi diri bila melakukan kesalahan dan perbuatan jahat maka akan merasakan panas api neraka di akherat kelak.

Ruang senapur juga memiliki fungsi sosial yaitu tempat berinteraksi dengan para tetangga baik pria maupun wanita. Bagi masyarakat sekitar rumah (dalam satu kampung) jika berkunjung ke salah satu rumah maka mereka cenderung menggunakan dapur untuk berinteraksi daripada menerima tamu di ruang tamu. Ini bermakna bahwa jika tamu yang diterima di ruang senapur maka orang tersebut dianggap sebagai orang dekat dan bukan orang asing lagi. Secara sederhana ruang senapur bisa dimaknai sebagai "isi perut" suatu 
rumah/keluarga. Dengan melihat ruang senapur kita bisa menakar kondisi keluarga tersebut, sehingga jika seorang tamu sudah memasuki ruang senapur maka pemilik rumah sudah menaruh kepercayaan kepada orang tersebut. Artinya jika kita sudah ditawari memasuki ruang senapur maka pemilik rumah sudah sangat menyukai dan merasa dekat dengan kita dan tidak lagi dianggap sebagai orang asing.

Seperti umumnya di berbagai daerah di Indonesia, dapur identik dengan kaum perempuan atau ibu-ibu. Mereka yang paling sering memanfaatkan dapur atau penguasa dapur. Seperti contoh dalam budaya masyarakat Jawa dikenal istilah konco wingking (teman di belakang) untuk menyebut istri/perempuan. Belakang di sini berarti dapur. Dengan demikian praktis dapur menjadi tempat pertemuan bagi sesama perempuan di satu lingkungan. Mereka saling bertukar informasi tentang berbagai hal. Mulai dari menu masakan, masalah keluarga, pertanian, hewan ternak, program televisi, hingga masalah politik.

Hal itu juga terjadi bagi kaum ibu di desa Tepal. Namun ada hal menarik yang patut dicontoh dari kebiasaan berkumpul di ruang senapur ibu-ibu Desa Tepal yaitu mereka tidak pernah membicarakan kejelekan orang lain (gosip). Ada keyakinan di masyarakat Tepal untuk harus selalu membicarakan hal-hal baik dan dianggap no terang (suatu hal yang tidak pantas/dilarang/gelap/negatif) jika membicarakan hal-hal buruk atau kejelekan orang lain. Selain itu juga, ruang senapur di Desa Tepal sangat berdekatan satu sama lain, sekitar dua sampai tiga meter, saling membelakangi rumah, sehingga percakapan di ruang dapur bisa terdengar oleh tetangga dekat, terlebih lagi hanya dibatasi dinding bambu.

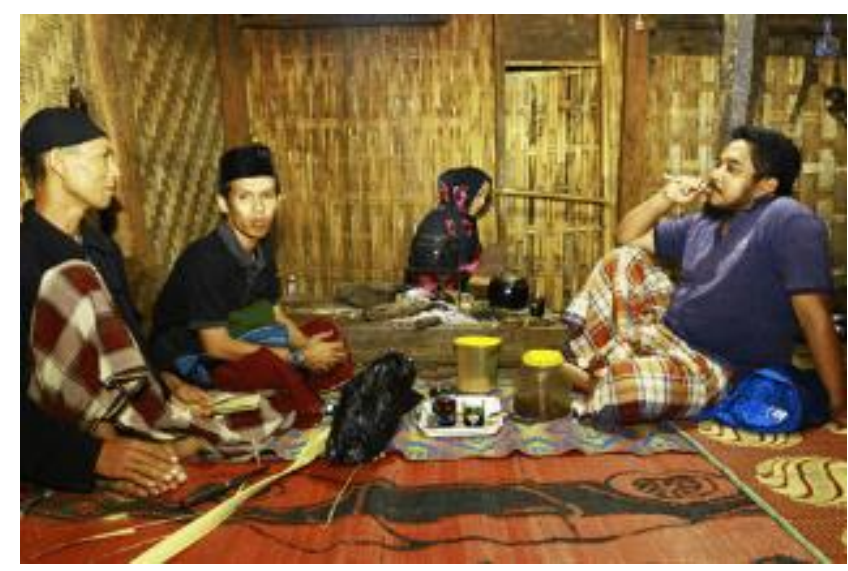

Gambar 4. Suasana ruang senapur (ruang privasi), menjadi ruang tamu (ruang publik terbatas) 


\section{0 \\ 4 \\ 000

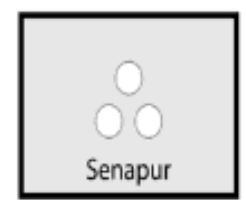

Gambar 5. Denah tempat duduk dilihat dari tingkat penghormatan sosial pemilik rumah terhadap tamu.

\section{Denotasi}

Senapur sebagai ruang privasi keluarga berubah menjadi ruang tamu (ruang publik terbatas), dimana tamu dipersilakan untuk masuk ke senapur dan dilayani sebaik mungkin serta dianggap sebagai keluarga sendiri. Posisi duduk para tamu menandakan tingkat penghargaan oleh pemilik rumah. Penghargaan tertinggi akan dipersilakan duduk di dekat senapur mendekati tungku api ( nomor 1), lalu penghargaan kepada orang tingkat kedua berada di sampingnya dan seterusnya sesuai dengan urutan nomor yang ada pada gambar di atas. Kepala rumah tangga atau bapak pemilik rumah biasanya duduk di no. 7 , dan Ina (ibu) atau istri pemilik rumah akan duduk di dekat senapur untuk memasak dan sekaligus memantau suasana senapur.

\section{Konotasi}

Masyarakat Tepal sangat menghormati tamu, bila ada tamu dari luar desa, mereka akan menawarkan rumahnya untuk menginap, dan juga menawarkan makan, walaupun kondisi rumah dan makanan seadanya, mereka berusaha menjamu tamu dengan sebaikbaiknya, bahkan sedikit berlebih dibandingkan dengan menu keseharian mereka. Bila sehari-harinya mereka sekeluarga makan dengan nasi, sayur blunak (pakis) dan sira wer (sambal khas Tepal), jika ada tamu, mereka akan berusaha menyembelih ayam sebagai tambahan menu untuk tamu. Mereka percaya dengan menjamu tamu di rumah, sebagai penanda status sosial lebih baik dan menjadi sebuah kehormatan di tengah masyarakat. Lebih daripada itu meraka percaya bahwa tamu merupakan pintu rizki, sekaligus juga implementasi sebuah bentuk nilai ibadah kepada Allah SWT.

Posisi ibu (wanita) yang mengatur dan memasak makanan merupakan posisi strategis dalam senapur, walaupun terlihat hanya sebagai orang yang memasak dan membagikan makanan tetapi sosok wanita bisa menjadi penentu kebijakan dalam masalah keluarga, seorang bapak sebagai kepala keluarga akan mengalah bila ada keputusan atau keinginan istri yang lebih dominan. Dalam konsep agama, ibu lebih mempunyai pengaruh dalam keluarga terutama bagi anak-anak, ibu lebih diikuti atau akan selalu diikuti pesannya, mereka percaya di bawah telapak kaki ibu ada syurga, jadi untuk mendapatkan syurga di kehidupan akhir nanti harus patuh terhadap ibu dan mengikuti keputusan ibu akan membuat kehidupan yang lebih baik. 


\section{Senapur}

Di dalam ruang senapur (dapur) ada tempat khusus tempat melakukan aktivitas memasak yang disebut senapur bagi masyarakat Tepal, namun di desa yang lain di Sumbawa dikenal dengan nama senikan.

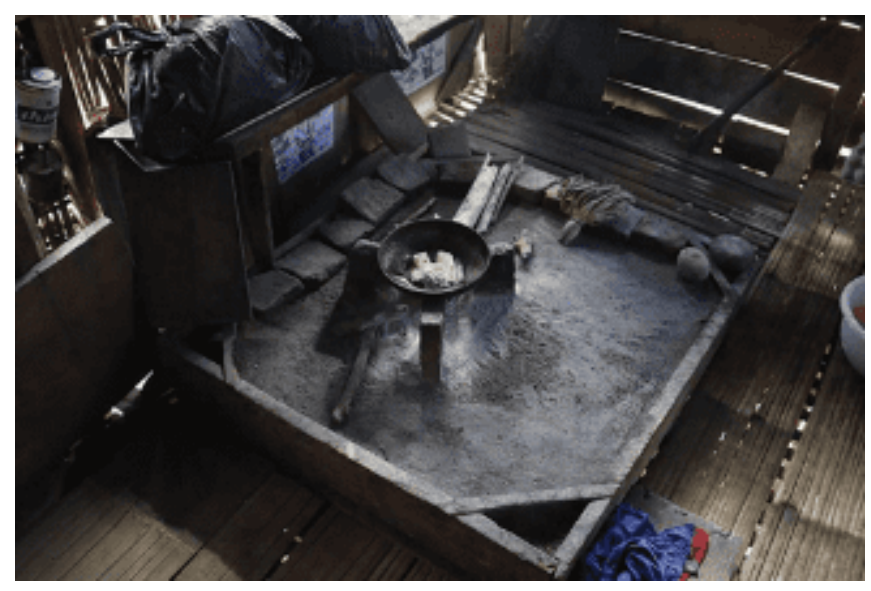

Gambar 6. Senapur atau tungku tempat memasak

\section{Denotasi}

Senapur berbentuk persegi menyerupai meja berbahan kayu khusus. Beberapa bahan yang dimasukkan di bawah senapur, yaitu daun kayu grusa atau bisa juga daun kayu jarak, besi bekas (bekas parang, bate, ladeng/pisau), pecahan genteng atau tembikar serta di bawahnya dilapisi bambu sebagai penahan tanah. Komponen-komponen itu berfungsi sebagai penahan hawa panas/api dan juga sebagai penawar hal-hal negatif (sihir).

\section{Konotasi}

Tanah untuk bahan pembuatan Senapur biasanya diambil dari luar pekarangan rumah karena dikhawatirkan terjadi hal-hal negatif. Batu senikan dari batu berongga agar kuat tidak muda pecah terkena api/panas. Namun seiring waktu, masyarakat Tepal sudah mulai banyak yang menggunakan besi sebagai tungku karena lebih praktis dan kuat

Pada saat memulai prosesi pembuatan senapur, diawali dengan niat, membaca Bismillahirrahmanirrahim dan salawat nabi "Allahumma Sholli 'ala sayyidina muhaammadin wa 'ala aali sayidina Muhammad". Bacaan ini diucapkan agar hajat atau keinginan bisa tercapai atas ijin Allah SWT. Setelah senapur selesai dibuat, maka diharuskan untuk segera dinyalakan, agar terhindar dari gangguan setan dan mahluk halus lainnya, karena sejatinya menunda pekerjaan yang baik adalah perbuatan (godaan) syaitan. Hal ini bermakna agar setiap pekerjaan selalu dikerjakan dengan baik dengan penuh perhitungan dan tidak menunda-nunda pekerjaan sampai pekerjaan itu diselesaikan dengan baik dan segera menyelesaikannya.

Masyarakat Tepal dalam hal memenuhi kebutuhan hidupnya sangat mandiri, mereka terbiasa memanfaatkan hal-hal yang ada dalam dirinya dan lingkungan alam sekitarnya. Termasuk juga dalam hal ukur-mengukur ketika akan membuat sesuatu dengan menggunakan ukuran tubuhnya untuk membuat dan ukuran, tidak menggunakan 
ukuran lazim digunakan seperti centimeter atau meter. Sebagai contoh ketika membuat senapur mereka menggunakan ukuran pengita otak, yakni menggunakan ukuran berdasarkan lingkar kepala (otak), dengan menggunakan jengkal tangan orang dewasa. Mengunakan sistem pengita otak, mengukur dengan jengkal kira-kira di tengah dahi, di atas titik tengah antara dua mata, tali diukur melingkar di kepala sampai ke titik awal di tengah dahi dari kepala ibu atau istri pemilik rumah. Lalu ukuran itu dikalikan tiga sebagai panjang senapur dan lebar menyesuikan panjang dapur dan luas ruangan dapur. Pengita otak merupakan bentuk ukuran dasar tentang cara pandang masyarakat Tepal, agar dalam melakukan sesuatu selalu dipikirkan dengan baik, lahir maupun batin, dampak buruk dan manfaatnya di kemudian hari.

Batu senapur, terdiri dari tiga batu, satu batu di bagian utara dan dua batu di bagian selatan. Batu senapur ini menandakan keseimbangan dua penjuru mata angin dan keseimbangan estetika dengan jumlah batu sebanyak tiga merupakan hitungan ganjil. Tiga batu tersebut sebagai pondasi kehidupan masyarakat Tepal tentang tiga tingkatan dalam menjalankan perintah agama yang mereka anut yakni Islam, Iman dan Ihksan. Pertama, makna Islam adalah melaksanakan lima rukun Islam, yaitu mengucapkan dua kalimat syahadat; bersaksi bahwa tiada Tuhan selain Allah, dan Muhammad sebagai utusan Allah, mendirikan sholat, menunaikan zakat, berpuasa di bulan ramadhan dan berhaji bila mampu. Kedua, makna Iman, yakni beriman kepada Allah SWT, para Malaikat-Nya, Kitab-kitab-Nya, para Rasul, hari akhir dan beriman terhadap Qodho dan Qodar. Ketiga, makna Ihksan, seorang manusia menyembah Tuhannya dengan ibadah yang sungguh-sungguh dan penuh rasa harap serta keinginan, seolah-olah dia melihatNya sehingga diapun sangat ingin sampai kepada-Nya. Jadi dengan tiga batu yang bermakna Islam, Iman dan Ikhsan bagi masyarakat Tepal merupakan pondasi dasar yang kuat untuk mengarungi kehidupan di dunia dan akherat.

Syariat Islam dilaksanakan secara total baik dalam pemerintahan maupun dalam adat istiadat dan kemasyarakatan. Sehingga lahirlah falsafah budaya Sumbawa Adat Barenti Ko Syara', Syara Barenti Ko Kitabullah (adat berpegang pada Syara', Syara berpegang kepada Kitabullah) untuk Kerik Salamat Tau Ke Tana Samawa (Keselamatan dan kesejahteraan bagi penduduk dan bumi Sumbawa).

\section{SIMPULAN}

Ruang senapur dan senapur dalam desain struktur rumah panggung Tepal tidak hanya memiliki fungsi teknis untuk aktivitas memasak atau tempat menyimpan bahanbahan makanan tetapi juga mempunyai fungsi sosial, budaya dan ritual. Ruang senapur sebagai ruang privasi menjadi ruang publik yang memiliki peran signifikan dalam interaksi sosial dengan masyarakat sekitar terlebih lagi terhadap tamu-tamu yang datang dari luar desa Tepal. Ruang Senapur dibuat dengan menggunakan material-material khusus yang memiliki fungsi dan tujuan tertentu serta memiliki makna sosiologis dan kosmologis.

Senapur juga menjadi bukti betapa masyarakat Tepal memiliki pemahaman dan kecerdasan sosial yang tinggi. Mereka memiliki cara tersendiri bagaimana menghargai tamu yang datang ke desa mereka. Mereka menyakini tamu adalah rezeki sehingga dengan memperlakukan tamu dengan baik maka sama dengan mempermudah datangnya rezeki dari yang maha kuasa. Penghargaan yang begitu tinggi terhadap tamu/orang lain merupakan karakter umum masyarakat Sumbawa yang egaliter. Mereka akan merasa 
gembira jika bisa membuat orang lain merasa nyaman selama berada di rumah/desa mereka. Dengan melihat realitas keberadaan senapur dari sisi fungsi teknis dan sosial dalam masyarakat Tepal, mereka benar-benar menjadikan senapur sebagai pusat kebudayaan mereka yang mampu membentuk perilaku, karakter masyarakat baik secara horizontal maupun vertikal.

\section{DAFTAR PUSTAKA}

Amir Piliang, Yasraf. 2003. Hipersemiotika;Tafsir Cultural Studies Atas Matinya Makna, Bandung; Jalasutra.

Berger, Arthur Asa. 2010. Pengantar Semiotika; Tanda-tanda dalam Kebudayaan Kontemporer. Yogyakarta: Tiara wacana.

Budiman, Kris. 2011. Semiotika Visual: Konsep, Isu, dan Problem Ikonitas. Yogyakarta: Jalasutra.

Danesi, Marcel. 2011. Pesan, Tanda Dan Makna (Buku Teks Dasar Mengenai Semiotika dan Teori Komunikasi). Yogyakarta: Jalasutra.

Fiske, Jhon. 2018. Pengantar Ilmu Komunikasi, Terj. Hapsari Dwiningtyas, Depok; Rajawali Pers.

Hoed, Benny H. 2014. Semiotik dan Dinamika Sosial Budaya.Jakarta: Kemunitas Bambu.

Ida, Rachmah. 2014. Metode Penelitian: Studi Media dan Kajian Budaya. Jakarta: Prenada Media Grup.

Kamus Besar Bahasa Indonesia. 1995/2nd ed. Departemen Pendidikan dan Kebudayaan: Jakarta.

Littlejhon, Stephen W, 2014, Teori Komunikasi, Theories of Human Communication. Jakarta: Salemba Humanika.

Vera, Nawiroh. 2014. Semiotika Dalam Riset Ilmu Komunikasi. Jakarta:Ghalia Indonesia. 